\title{
Doenças Fúngicas Pós-Colheita em Mamões e Laranjas Comercializados na Central de Abastecimento do Recife
}

\author{
Suzana A. F. Dantas, Sônia M. A. Oliveira, Sami J. Michereff, Luciana C. Nascimento, Luciana M. S. \\ Gurgel \& Wagner R. L. S. Pessoa
}

Universidade Federal Rural de Pernambuco, DEPA-Fitossanidade, CEP 52171-900, Recife, PE, Fax (081) 3302-1205, e-mail: suzanaalencar@globo.com

(Aceito para publicação em 24/06/2003)

Autor para correspondência: Suzana Alencar Freire Dantas

DANTAS, S.A.F., OLIVEIRA, S.M.A., MICHEREFF, S.J., NASCIMENTO, L.C., GURGEL, L.M.S. \& PESSOA, W.R.L.S. Doenças fúngicas pós-colheita em mamões e laranjas comercializados na Central de Abastecimento do Recife. Fitopatologia Brasileira 28:528-533. 2003.

\section{RESUMO}

Doenças fúngicas pós-colheita constituem uma das principais causas de perdas durante a fase de comercialização de frutos tropicais. Frutos de mamão (Carica papaya) e laranja (Citrus spp.) foram analisados em relação à incidência de doenças fúngicas e frequiência das espécies patogênicas durante seis meses, na Central de Abastecimento de Recife, Estado de Pernambuco. As amostragens foram realizadas mensalmente, sendo avaliados 40 frutos de cada espécie, em cinco pontos de comercialização, totalizando 200 frutos/ amostragem/espécie. Ocorreu uma grande diversidade de doenças em frutos de mamão, onde as incidências variaram entre 39,71\% e $0,07 \%$, com maior nível para a podridão peduncular. Em frutos de laranja a incidência de doenças variou entre $11,85 \%$ e $0,62 \%$, para podridão peduncular por Lasiodiplodia spp. e antracnose, respectivamente. Os patógenos que apresentaram maiores freqüências foram Colletotrichum gloeosporioides (44,95\%) em mamão e Lasiodiplodia theobromae $(11,85 \%)$ em laranja. A diversidade de doenças constatada neste estudo sugere a necessidade do emprego de medidas de controle mais efetivas durante as fases de produção e pós-colheita de frutos de mamão e laranja, visando propiciar redução das perdas.

Palavras-chave adicionais: fungos fitopatogênicos, Carica papaya, Citrus sinensis.

\section{ABSTRACT}

Post harvest fungal diseases in papaya and orange marketed in the Distribution Centre of Recife

Fungal diseases constitute one of the main causes of losses during commercialization of tropical fruits. Papaya (Carica papaya) and orange (Citrus spp.) fruits were analyzed in relation to the disease incidence and frequency of the pathogenic species for six months, in the Distribution Centre of the city of Recife, Pernambuco, Brazil. Forty fruits of each species were evaluated monthly at five commercialization points, for a total of 200 fruits/month/species. A great diversity of diseases occurred in papaya fruits, where incidences ranged from $39,71 \%$ to $0,07 \%$, with the higher level for stem-end rot. In orange fruits the disease incidence was $11,85 \%$ and $0,87 \%$, for Lasiodiplodia stem-end rot and antracnose, respectively. The pathogens that presented higher frequencies were Colletotrichum gloeosporioides $(44,95 \%)$ in papaya and Lasiodiplodia theobromae $(11,85 \%)$ in orange. The diversity of diseases verified in this study suggests a need for more effective control measures during the production and postharvest phases of papaya and orange, seeking to propitiate reduction of the losses.

\section{INTRODUÇÃO}

O Brasil destaca-se como o segundo maior produtor mundial de frutas, onde frutos de mamoeiro (Carica papaya L.) contribuem com uma produção de 1.450.000 toneladas métricas/ano e frutos cítricos (Citrus spp.) com 16.923.732 toneladas métricas/ano (FAO, 2002). Apesar dessa elevada produção de frutas tropicais, ocorre um grande volume de perdas, que corresponde em média a $30 \%$ do total produzido (Benato, 1999).

As perdas pós-colheita podem ter causas diversas, dentre as quais se destacam as doenças (0Chitarra \& Chitarra, 1990), onde as ocasionadas por fungos ocorrem com maior freqüência e atividade (Booth \& Burden, 1986), sendo responsáveis por 80 a $90 \%$ do total de perdas causadas por fitopatógenos (Gullino, 1994). Em frutos de mamão e laranja, esses fitopatógenos causam consideráveis perdas pós-colheita, podendo atingir $75 \%$ na fase de comercialização do mamão (Paull et al., 1997) e 50\% na de laranja (Eckert, 1993).

As doenças pós-colheita podem iniciar no campo e ficarem latentes, manifestando-se somente após a colheita em condições ambientais favoráveis (Gomes, 1996). A penetração do hospedeiro pelo patógeno pode ocorrer diretamente via epiderme, pela cutícula intacta, bem como por ferimentos ou aberturas naturais na superfície dos frutos, como as lenticelas (Eckert, 1980; Zambolim et al., 2002). As infecções latentes podem iniciar em qualquer estádio do fruto na planta, ocorrendo a inibição do desenvolvimento do patógeno através de condições fisiológicas impostas pelo hospedeiro, até que o estádio de maturação do fruto tenha sido alcançado e/ou iniciada a respiração climatérica (Prusky, 1996).

As infecções ativas ou não latentes ocorrem quando 
os frutos já iniciaram ou completaram o processo de maturação, progredindo na medida em que as condições ambientais favorecem o crescimento do patógeno. Nessas infecções, a penetração se processa principalmente por ferimentos causados durante as operações de colheita, armazenamento e comercialização (Cappelini \& Ceponis, 1984), embora em alguns casos possa ocorrer pela superfície intacta do fruto (Benato, 1999). Mudanças fisiológicas normais do hospedeiro, manuseio incorreto ou condições ambientais adversas podem dar início a transição da fase de latência para a fase ativa, promovendo o desenvolvimento da doença (Cappellini \& Ceponis, 1984; Jarvis, 1994).

Pesquisas envolvendo identificação, caracterização e quantificação de patógenos causadores de doenças póscolheita em frutos são escassos e não sistemáticos (Silveira $e t$ al., 2001). Neste contexto, este trabalho teve como objetivo efetuar levantamentos para identificar e quantificar a incidência de doenças fúngicas pós-colheita em frutos de mamão e laranja, na Central de Abastecimento do Recife, Estado de Pernambuco, Brasil.

\section{MATERIAL E MÉTODOS}

\section{Ocorrência de doenças fúngicas pós-colheita em frutos de laranja e mamão}

Amostras de frutos de mamão (cv. Sunrise Solo) e laranja (cv. Pêra), coletados na Central de Abastecimento da cidade do Recife (CEASA), Estado de Pernambuco, foram avaliadas quanto à ocorrência de infecções latentes e/ou ativas. As amostragens foram realizadas mensalmente, durante o período de seis meses, de julho a dezembro de 2000, sendo analisados 200 frutos/amostragem/espécie, com um total de 1.200 frutos analisados, distribuídos em cinco pontos de comercialização, onde foram coletados ao acaso 40 frutos de cada espécie. Os frutos coletados foram lavados com água e sabão, postos a secar por 30 min e, em seguida, incubados sobre a base de placas de Petri contendo algodão hidrófilo umedecido com água destilada esterilizada, sendo o conjunto envolto com saco plástico, constituindo a câmara úmida. Decorrido o período de $24 \mathrm{~h}$, a câmara úmida foi removida e os frutos mantidos em condições de temperatura ambiente $\left(28 \pm 2{ }^{\circ} \mathrm{C}\right)$ por cinco dias. Após esse período, os frutos foram avaliados quanto à incidência de doenças fúngicas, caracterizadas pela porcentagem de frutos com sintomas de cada doença.

\section{Identificação e freqüiência de fungos causadores de doenças pós-colheita}

Os frutos com sintomas de doenças fúngicas em póscolheita tiveram os possíveis agentes desses sintomas isolados em laboratório. Os procedimentos de isolamento constaram da desinfestação superficial de fragmentos de tecidos lesionados com solução de $\mathrm{NaClO}$ água destilada esterilizada na proporção de 1:3 (v:v) por um minuto e lavagem por duas vezes em água destilada esterilizada, seguida do plaqueamento dos fragmentos em meio batata-dextrose-agar (BDA), suplementado com $0,01 \%$ de cloranfenicol. As placas foram incubadas por oito dias, à temperatura de $28 \pm 2{ }^{\circ} \mathrm{C}$, sob alternância luminosa (12 h luz/12 h escuro).

Para avaliação da patogenicidade dos isolados fúngicos obtidos, foram seguidos os postulados de Koch, sendo utilizados frutos maduros e sadios de mamão e/ou laranja, desinfestados como descrito anteriormente. Sob condições assépticas, em câmara de fluxo laminar, em cada fruto foram selecionados quatro pontos e efetuados ferimentos de aproximadamente $3 \mathrm{~mm}$ de profundidade, com auxílio de estilete flambado. Em cada ponto selecionado foi depositado um disco de BDA com $5 \mathrm{~mm}$ de diâmetro contendo estruturas do fungo teste. Os frutos inoculados foram mantidos em câmara úmida, sendo observados diariamente para verificação do aparecimento de sintomas e reisolamento dos patógenos. $\mathrm{Na}$ identificação dos fungos foram adotados critérios estabelecidos internacionalmente (Rossman et al., 1994), com base nas observações micromorfológicas das culturas.

A frequiência de fungos fitopatogênicos foi expressa como a porcentagem de frutos dos quais cada espécie fúngica foi isolada e a patogenicidade confirmada.

\section{Análises estatísticas}

O delineamento experimental foi em blocos ao acaso, com cinco repetições, sendo cada repetição constituída por um ponto de comercialização onde foram avaliados 40 frutos/ espécie. Os dados de incidência das doenças e freqüência dos fungos, obtidos em cada ponto de comercialização, foram submetidos à análise de variância, seguida por separação de médias pelo teste de Tukey $(0,05 \%)$.

\section{RESULTADOS E DISCUSSÃO}

\section{Incidência de doenças pós-colheita em frutos de mamão e laranja}

Os frutos de mamão apresentaram elevada incidência de diferentes doenças fúngicas pós-colheita (Tabela 1), atingindo $82,53 \%$ dos frutos amostrados, enquanto em laranja foram detectadas doenças em $21,85 \%$ dos frutos analisados. Os resultados obtidos confirmam a importância econômica das doenças em pós-colheita de frutos de mamão e laranja, pois a maioria dessas doenças desqualifica a fruta para comercialização, como foi destacado por Paull et al. (1997) e Eckert (1993), que mencionaram perdas de até 75\% para mamão e $50 \%$ para laranja, durante o período de comercialização. A maior incidência de doenças em frutos de mamão é compreensível, uma vez que a casca dessa espécie não possui grande resistência que impeça a penetração de patógenos (Gayet et al., 1995).

Foram verificadas diferenças significativas $(\mathrm{P}=0,05)$ entre os períodos de coleta de frutos em relação à incidência das podridões por Fusarium sp., Geotrichum sp., Phytophthora sp. e Phomopsis sp.em mamão, bem como de podridões causadas por Lasiodiplodia sp. e Phomopsis sp. em laranja. Essas diferenças, provavelmente, se devem às condições ambientais em cada mês de amostragem, pois a freqüência e a intensidade das doenças são fortemente 
S.A.F. Dantas et al.

TABELA 1 - Incidência de doenças fúngicas pós-colheita em frutos de mamão (Carica papaya) e laranja (Citrus spp.) na Central de Abastecimento do Recife, Estado de Pernambuco, Brasil

\begin{tabular}{|c|c|c|c|c|c|c|c|}
\hline \multirow{3}{*}{ Doença } & \multicolumn{7}{|c|}{ Percentagem de Incidência ${ }^{1}$} \\
\hline & julho & agosto & setembro & outubro & novembro & dezembro & Media \\
\hline & \multicolumn{7}{|c|}{ Mamão } \\
\hline Podridão peduncular & $42,82 \mathrm{a}^{2}$ & $33,30 \mathrm{a}$ & $26,27 \mathrm{a}$ & $50,00 \mathrm{a}$ & $45,99 \mathrm{a}$ & $39,86 \mathrm{a}$ & $39,71 \mathrm{~A}$ \\
\hline Antracnose & $28,78 \mathrm{a}$ & $24,10 \mathrm{a}$ & $13,24 \mathrm{a}$ & $14,48 \mathrm{a}$ & $29,75 \mathrm{a}$ & $11,60 \mathrm{a}$ & $20,32 \mathrm{~B}$ \\
\hline Mancha chocolate & $16,10 \mathrm{a}$ & $27,25 \mathrm{a}$ & $1,23 \mathrm{a}$ & $17,80 \mathrm{a}$ & $0,00 \mathrm{a}$ & $0,41 \mathrm{a}$ & $10,46 \mathrm{C}$ \\
\hline Podridão por Fusarium & $1,43 \mathrm{~b}$ & $13,69 \mathrm{a}$ & $7,96 \mathrm{ab}$ & $4,31 \mathrm{ab}$ & $4,42 \mathrm{ab}$ & $1,62 \mathrm{~b}$ & $5,57 \mathrm{CD}$ \\
\hline Podridão por Geotrichum & $4,25 \mathrm{ab}$ & $7,98 \mathrm{a}$ & $0,10 \mathrm{bc}$ & $0,00 \mathrm{c}$ & $0,00 \mathrm{c}$ & $0,00 \mathrm{c}$ & 2,05 CDE \\
\hline Podridão aquosa & $0,40 a b$ & $0,00 \mathrm{~b}$ & $1,17 \mathrm{ab}$ & $4,54 \mathrm{a}$ & $2,34 \mathrm{ab}$ & $0,58 \mathrm{ab}$ & $1,50 \mathrm{CDE}$ \\
\hline Podridão por Phytophthora & $0,59 \mathrm{ab}$ & 7,66 a & $0,00 \mathrm{~b}$ & $0,00 \mathrm{~b}$ & $0,10 \mathrm{~b}$ & $0,00 \mathrm{~b}$ & $1,39 \mathrm{CDE}$ \\
\hline Podridão seca & $0,00 \mathrm{a}$ & $0,00 \mathrm{a}$ & $1,17 \mathrm{a}$ & $1,48 \mathrm{a}$ & $2,34 \mathrm{a}$ & $0,90 \mathrm{a}$ & $0,98 \mathrm{CDE}$ \\
\hline Podridão por Curvularia & $0,00 \mathrm{a}$ & $0,00 \mathrm{a}$ & $1,43 \mathrm{a}$ & $0,00 \mathrm{a}$ & 0,00 a & $0,00 \mathrm{a}$ & $0,24 \mathrm{DE}$ \\
\hline Podridão por Lasiodiplodia & $0,41 \mathrm{a}$ & $0,00 \mathrm{a}$ & $0,20 \mathrm{a}$ & $0,40 \mathrm{a}$ & $0,00 \mathrm{a}$ & $0,10 \mathrm{a}$ & $0,17 \mathrm{E}$ \\
\hline Podridão verde & $0,00 \mathrm{a}$ & $0,00 \mathrm{a}$ & $0,20 \mathrm{a}$ & $0,10 \mathrm{a}$ & $0,00 \mathrm{a}$ & $0,10 \mathrm{a}$ & $0,07 \mathrm{E}$ \\
\hline \multirow[t]{2}{*}{ Podridão por Alternaria } & $0,00 \mathrm{a}$ & $0,40 \mathrm{a}$ & $0,00 \mathrm{a}$ & $0,00 \mathrm{a}$ & $0,00 \mathrm{a}$ & $0,00 \mathrm{a}$ & $0,07 \mathrm{E}$ \\
\hline & \multicolumn{7}{|c|}{ Laranja } \\
\hline Podridão peduncular por Lasiodiplodia & $11,37 \mathrm{ab}$ & $13,84 \mathrm{ab}$ & $12,46 \mathrm{ab}$ & $19,82 \mathrm{a}$ & $5,19 \mathrm{~b}$ & $8,41 \mathrm{ab}$ & $11,85 \mathrm{~A}$ \\
\hline Podridão verde & $6,81 \mathrm{a}$ & $6,31 \mathrm{a}$ & $6,24 \mathrm{a}$ & $2,62 \mathrm{a}$ & $0,40 \mathrm{a}$ & $0,81 \mathrm{a}$ & $3,86 \mathrm{~B}$ \\
\hline Podridão peduncular por Phomopsis & $1,82 \mathrm{~b}$ & $10,32 \mathrm{a}$ & $2,34 \mathrm{ab}$ & $3,49 a b$ & $1,60 \mathrm{~b}$ & $0,20 \mathrm{~b}$ & $3,29 \mathrm{~B}$ \\
\hline Podridão azeda & $3,40 \mathrm{a}$ & $0,40 \mathrm{a}$ & $1,48 \mathrm{a}$ & $4,23 \mathrm{a}$ & $0,10 \mathrm{a}$ & $2,28 \mathrm{a}$ & $1,98 \mathrm{BC}$ \\
\hline Antracnose & $1,60 \mathrm{a}$ & $0,00 \mathrm{a}$ & $0,10 \mathrm{a}$ & $1,74 \mathrm{a}$ & $0,40 \mathrm{a}$ & $1,41 \mathrm{a}$ & $0,87 \mathrm{C}$ \\
\hline
\end{tabular}

${ }^{1}$ Media de cinco repetições em porcentagem, considerando 200 frutos/amostra.

${ }^{2}$ Medias seguidas pela mesma letra minúscula nas linhas (entre coletas) e maiúscula na coluna de médias, não diferem entre si, pelo teste de Tukey $(\mathrm{P}=0,05)$. Dados transformados em arco seno $\sqrt{\mathrm{x}} / 100$.

influenciadas pela variação ambiental imposta durante todas as etapas da pré e pós-colheita (Agrios, 1997).

Em frutos de mamão, a podridão peduncular apresentou a maior incidência média $(39,71 \%)$, seguida da antracnose $(20,32 \%)$, diferindo significativamente $(\mathrm{P}=0,05)$ entre si e das demais doenças. Foi constatado que na podridão peduncular estavam envolvidos diferentes patógenos, tais como Colletotrichum gloeosporioides (Penz.) Penz. \& Sacc., Fusarium spp., Phoma caricae-papayae (Tarr.) Punithalingam, Lasiodiplodia theobromae (Pat.) Griffon \& Maulb, Phomopsis caricae-papayae Petr. \& Cif., Rhizopus stolonifer (Ehrenb., Fr.) Vuill., Phytophthora palmivora Butler e Pestalotia sp. (Figura 1), assemelhando-se ao relatado em outros estudos com frutos de mamão (Medina, 1989; Gayetetal., 1995; Benato, 1999; Gellen et al., 2000; Nery-Silva et al., 2001). No Brasil, Peres et al. (2000) apontaram Fusarium como o gênero de maior ocorrência, seguido de Phoma, enquanto no Havaí este último foi o mais registrado (Snodow, 1990; Gellenet al., 2000). Nas Filipinas, foi verificada maior ocorrência de L. theobromae (Lantican \& Quimio, 1976), enquanto na Índia e nos Estados Unidos da América de L. theobromae e P. caricae-papayae (Gupta \& Nema, 1979) foram os mais freqüentes.

A mancha chocolate apresentou incidência média de $10,45 \%$, sem diferir significativamente $(\mathrm{P}=0,05)$ das podridões por Fusarium sp. $(5,57 \%)$, Geotrichum sp. $(2,05 \%)$ e Phytophthora sp. $(1,39 \%)$, bem como das podridões aquosa $(1,50 \%)$ e seca $(0,98 \%)$.

A antracnose juntamente com a mancha chocolate somaram uma incidência de $30,78 \%$, resultado este similar ao obtido por Gellen et al. (2000), que relatou a antracnose como a doença apresentando maior incidência na pós-colheita de mamão "Surise Solo". Ocorrem divergências com relação ao agente causal da mancha chocolate, pois Medina (1989) considera que a antracnose é causada por C. gloeosporioides e a mancha chocolate por uma raça fisiológica diferenciada deste patógeno. Jeffries et al. (1990) consideram a mancha chocolate como um tipo diferente de sintoma causado por $C$. gloeosporioides. A antracnose é considerada a doença póscolheita mais importante de frutos de mamão em quase todas as regiões produtoras, uma vez que frutos infetados tornamse imprestáveis à comercialização (Snowdon, 1990).

Embora a podridão por Fusariumsp. tenha apresentado o quarto maior nível de incidência em frutos de mamão, as perdas ocasionadas em pós-colheita são pouco expressivas, pois, geralmente, essa doença ocorre como um fator secundário, associada a lesões causadas por outros patógenos (Rezende \& Fancelli, 1997). Eventualmente, durante o armazenamento, frutos intactos podem se tornar susceptíveis à penetração direta pelo fungo (Agrios, 1997). Por outro lado, podem ser produzidas micotoxinas que tornam o fruto impróprio para o consumo (Snodow, 1990). Associadas à podridão por Fusarium sp. foram identificadas como espécies patogênicas $F$. solani (Mart.) Appel \& Wollenw., F. equiseti (Corda) Sacc., F. semitectum Berk. \& Rav. e F. anthofhilum (A. Braun) Wollenw. Resultados concordante com relatos que apontam várias espécies de Fusarium, ocasionando podridões em frutos de mamão (Snowdon, 1990).

A podridão por Geotrichum sp., causada por $G$. candidum Link. ex Pers., ainda não havia sido relatada na literatura especializada como ocorrente em frutos de mamão. 
Doenças fúngicas pós-colheita em frutos de mamão e laranja...

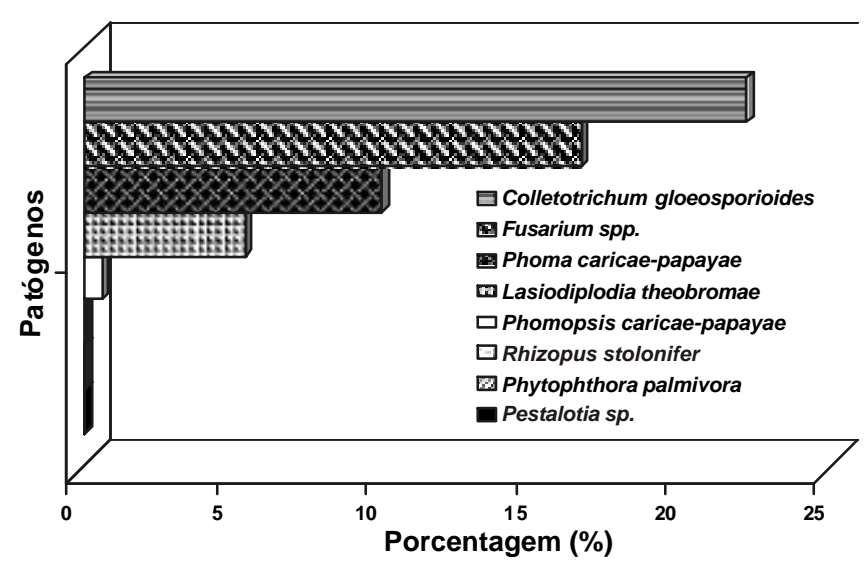

FIG. 1 - Freqüência de patógenos fúngicos da podridão peduncular em frutos de mamão (Carica papaya) na Central de Abastecimento do Recife, Estado de Pernambuco, Brasil.

Em outras frutas, essa doença não é controlada eficientemente com os tratamentos tradicionais empregados em pós-colheita, exigindo controle específico (Eckert, 1993).

A podridão por $P$. palmivora é mais freqüente em períodos chuvosos e quentes, sendo iniciada quando esporângios disseminados pelo vento alcançam a superfície de frutos verdes, apresentando lesões encharcadas e exudação de latéx (Silva, 2000). Durante a comercialização, os frutos maduros se recobrem rapidamente de um crescimento micelial branco ocasionando perdas, que apesar de não ter dados estatísticos no Brasil, existem registros de perdas com cerca de 7 a 10\% (Liberato et al., 1993).

A podridão aquosa causada por $P$. caricae-papayae, pode provocar danos significativos. É comum infecções latentes que, após a colheita, desenvolvem-se rapidamente por toda a polpa da fruta, desqualificando-a para a comercialização (Medina, 1989).

Outras doenças foram constatadas sobre frutos de mamão, porém com incidência inferior a $1 \%$ (Tabela 1), tais como a podridão seca ( $P$. caricae-papayae), a podridão por Curvularia sp., a podridão por L. theobromae, a podridão por A. alternata (Fr.) Keissler e a podridão verde (Penicillium digitatum Sacc.). Dentre essas, a podridão seca destaca-se porque pode ocasionar danos sobre os frutos, resultando em sérias perdas (Snodow, 1990). Da mesma forma, o patógeno que causa esta doença, assim comoL. theobromae, é de maior ocorrência no pedúnculo. A podridão por Curvularia, até então não descrita em pós-colheita sobre frutos de mamão, ocorreu em infecções mistas, contribuindo para a deterioração do fruto concomitantemente com outras doenças. A podridão por Alternaria normalmente restringe-se à superfície da fruta, podendo se tornar problema somente quando as frutas são armazenadas sob refrigeração, como relataram Medina (1989) e Snodow (1990).

Em frutos de laranja, a podridão peduncular por Lasiodiplodia, causada por L. theobromae, ocorreu em maior incidência $(11,85 \%)$, diferindo significativamente das demais doenças (Tabela 1). Essa predominância está em desacordo com os trabalhos de alguns autores que consideraram a podridão verde causada por $P$. digitatum, como a de maior incidência e mais destrutiva das doenças pós-colheita em citros, podendo ocorrer perdas de até $90 \%$ durante as fases de transporte, armazenamento e comercialização (Agrios, 1997; Franco \& Bettiol, 2000). A elevada incidência da podridão peduncular por Lasidiplodia pode ser explicada devido a temperatura do local de armazenamento, em torno de $30{ }^{\circ} \mathrm{C}$, mais favorável ao desenvolvimento do patógeno, aliado ao uso do etileno, que causa a abscisão precoce do botão, facilitando a entrada do patógeno que se encontra latente nos tecidos necróticos do botão (Barmore \& Brown, 1985). Assim, a redução das perdas por essa doença, entre outras práticas, pode ser conseguida mediante uma diminuição da aplicação do etileno, colhendo os frutos no ponto de comercialização, já que o aumento de incidência está relacionado com a quantidade de etileno empregado para aumentar a coloração da casca.

É provável que a baixa incidência de podridão verde $(3,86 \%)$ reflita os descartes realizados na Central de Abastecimento do Recife dos frutos de laranja com sintomas da doença, tendo em vista que se trata de sintomas facilmente reconhecidos. Em adição, $P$. digitatum produz várias micotoxinas, como a patulina, que contamina sucos feitos de frutos parcialmente infetados por $P$. digitatum, provocando vários distúrbios, inclusive câncer em seres humanos (Agrios, 1997).

A podridão peduncular por Phomopsis citri Fawcett, apesar de ter apresentado incidência de 3,29\% em frutos de laranja, não causa perdas tão grandes como aquelas ocasionadas por L. theobromae. Ao contrário desse patógeno, $P$. citri avança em direção à região central do fruto lentamente $\mathrm{e}$, raramente, atinge a extremidade estilar, causando perdas de maiores proporções somente quando os frutos demoram a ser comercializados (Feichtenberger et al., 1997). A ocorrência desses dois patógenos causadores de podridão peduncular neste estudo ocorreu isoladamente (Tabela 1), entretanto eles podem ocorrer em infecções mistas, onde a freqüência de cada um tem importância segundo a região de ocorrência (Snowdon, 1990). Na Austrália e no Japão, Phomopsis sp. é mais importante (Singh et al., 1977), enquanto no Sul da África e Israel, Lasiodiplodia sp. predomina (Zaubermanns \& Barkai-Golan, 1975).

A podridão azeda causada por G. candidum, apresentou incidência média de $1,98 \%$ em frutos de laranja, não diferindo significativamente $(\mathrm{P}=0,05)$ da antracnose (Tabela 1$)$. $\mathrm{O}$ resultado obtido para esta doença difere dos encontrados por Brown \& Eckert (1988) e Eckert (1993), que consideraram a podridão azeda como a segunda doença mais importante na pós-colheita em frutos cítricos, podendo causar perdas consideráveis. Foi verificada uma baixa incidência de antracnose $(0,87 \%)$, similarmente ao referido por Brown \& Eckert (1988), que consideraram a antracnose em pós-colheita de citros como uma infecção secundária, sem ocasionar perdas significativas. 
Freqüência de fungos causadores de doenças pós-colheita em frutos de mamão e laranja

Entre os patógenos detectados em frutos de mamão, $C$. gloeosporioides apresentou a maior freqüência $(44,95 \%)$, diferindo significativamente $(\mathrm{P} \leq 0,05)$ das demais (Figura 2$)$. Esse resultado reflete a participação de $C$. gloeosporioides como agente causal de várias doenças, como a podridão peduncular, a antracnose e a mancha chocolate, confirmando as observações de diversos autores (Medina, 1989; Jeffries et al., 1990; Ploetz et al., 1994).

Fusarium spp., P. caricae-papayae e L. theobromae apresentaram freqüências de $21,08 \%, 10,82 \%$ e 4,54\%, respectivamente, ocorrendo na superfície do fruto e no pedúnculo do mamão, sendo que os dois últimos, juntamente com $P$. caricae-papayae, foram mais freqüentes em podridões pedunculares (Figura 1 e 2), como já relatado por alguns autores (Medina, 1989; Snodow, 1990; Nishijima, 1994).

Uma considerável freqüência foi verificada para $G$. candidum (2,05\%), o qual constitui mais um problema dentre as doenças pós-colheita em frutos de mamão. Freqüências baixas sem diferenças significativas entre si $(\mathrm{P}>0,05)$ foram observadas para P.palmivora (0,34\%), Curvularia $\mathrm{sp.}(0,39 \%)$,

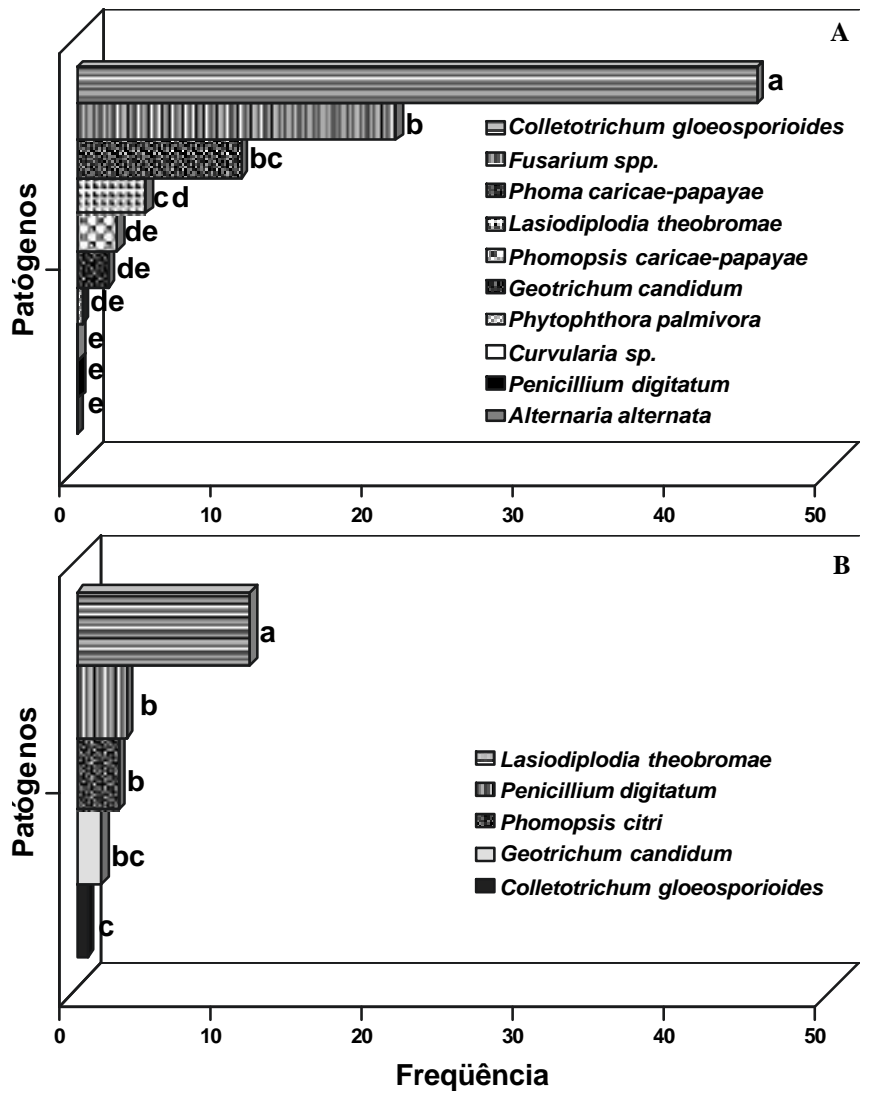

FIG. 2 - Freqüência de patógenos fúngicos em frutos de mamão (Carica papaya) (A) e laranja (B) na Central de Abastecimento do Recife, Estado de Pernambuco, Brasil. Medias seguidas da mesma letra não diferem significativamente entre si pelo teste de Tukey $(\mathrm{P}=0,05)$. Para efeito de análises, os dados foram transformados em arc seno $(\mathrm{x} / 100)^{1 / 2}$.
P. digitatum $(0,32 \%)$ e Alternaria sp. $(0,01 \%)$, porém contribuíram sinergisticamente para aumentar as perdas póscolheita de mamão.

As frequiências observadas dos patógenos fúngicos em frutos de laranja atingiram os mesmos valores verificados para a incidência das doenças causadas por esses patógenos (Tabela 1; Figura 2), pois cada patógeno causou somente um tipo de doença, diferente do verificado em frutos de mamão, onde o mesmo patógeno foi responsável por mais de uma doença.

Os índices de perdas de frutos em pós-colheita são geralmente reflexos dos percentuais de incidência das doenças verificados nessa fase, uma vez que os frutos são desqualificados para comercialização pela simples presença dos sintomas, independente da intensidade das mesmas (Ceponis \& Ceponis, 1985; Gullino, 1994). Assim, a grande diversidade de doenças pós-colheita provenientes de infecções latentes e/ou ativas constatada neste estudo sugere a necessidade do emprego de medidas de controle mais efetivas durante as fases de produção e pós-colheita de frutos de mamão e laranja, incluindo práticas de sanitização e métodos que induzam resistência dos frutos aos patógenos, visando propiciar a redução dessas perdas.

\section{REFERÊNCIAS BIBLIOGRÁFICAS}

AGRIOS, G.N. Plant pathology. 4. ed. San Diego. Academic Press. 1997.

BARMORE, C.R. \& BROWN, G.E. Influence of ethylene on increased susceptibility of oranges to Diplodia natalensis. Plant Disease 69:228230. 1985.

BENATO, E.A. Controle de doenças pós-colheita em frutos tropicais. Summa Phytopathologica 25:90-93. 1999.

BOOTH, R.H. \& BURDEN, O.J. Pérdidas de postcosacha. In: The Commonwealth Mycological Institute (Eds.) Manual para patologos vegetales. Kew. CAB/FAO. 1986. pp.162-179.

BROWN, GE. \& ECKERT, J.W. Diplodia stem-end rot. In: Whiteside, J.O., Garnsey, S.M. \& Timmer, L.W. (Eds.) Compendium of citrus diseases. St. Paul. APS Press. 1988. pp.33-34.

CAPPELLINI, R.A. \& CEPONIS, M.J. Postharvest losses in fresh fruits and vegetables:postharvest losses in perishable crops. In: Moline, H.E. (Ed.) Postharvest pathology of fruits and vegetables: postharvest losses in perishable crops. Berkeley. University of California Agricultural Experiment Station. 1984. pp.24-30.

CHITARRA, M.I.F. \& CHITARRA, A.B. Pós-colheita de frutos e hortaliças - fisiologia e manuseio. Lavras. ESAL/FAEPE. 1990.

ECKERT, J.W. Postharvest disease of fresh fruits and vegetables etiology and control. In: Haard, N.F. \& Salunkhe, D.K. (Eds.) Postharvest biology and handling of fruits and vegetables. Westport. The Avi. 1980. pp.81-117.

ECKERT, J.W. Post-harvest diseases of citrus fruits. Agriculture Outlook 54:225-232. 1993.

FAO. FAOSTAT - Agricultural statistics database. Rome. World Agricultural Information Center. 2002. (http://apps.fao.org. - versão 28/03/2002).

FEICHTENBERGER, E., MÜLLER, G.W. \& GUIRADO, N. 
Doenças dos citros (Citrus spp.). In: Kimati, H., Amorim, L., Bergamin Filho, A., Camargo, L.E.A. \& Rezende, J.A.M. (Eds.) Manual de Fitopatologia - doenças das plantas cultivadas. São Paulo. Agronômica Ceres. 1997. pp.261-296.

FRANCO, D.A.S. \& BETTIOL, W. Controle de bolor verde em póscolheita de citros com produtos alternativos. Fitopatologia Brasileira 25:602-606. 2000.

GARDNER, P.D., ECKERT, J.W., BORITELLE, J.L. \& BONCROFT, M.N. Management strategis for control of Penicillium decay in limon packing-houses:economic benefits. Crop Protection 5:26-32. 1986.

GAYET, J.P. \& BLEIN, R. Mamão para exportação:procedimentos de colheita e pós-colheita. Brasília. Embrapa-SPI. 1995.

GELLEN, G, RAMOS, V.H.V., JUNQUEIRA, N.T.V., \& FARIA, N.G. Conservação pós-colheita de mamão "sunrise solo" procedencias, ambientes de armazenamento e efeito do tiabendazole. Resumos, XVI Congresso Brasileiro de Fruticultura, Fortaleza, CE. 2000. p.389

GOMES, M.S.O. Conservação pós-colheita:frutas e hortaliças. Brasília. Embrapa-SPI. 1996. 134 p.

GULLINO, M.L. Lotta biologica a funghi agenti di marciumi della frutta in post-raccolta. Informatore Fitopatolico 4:5-13. 1994.

GUPTA, O. \& NEMA, K.G. Effect of different temperature and relative humidity on the development of fruit rots of papaya caused by Botryodiplodia theobromae and Colletotrichum gloeosporioides. Indian Phytopathology 32:106-107. 1979.

JARVIS, W.R. Latent infections in pre and postharvest environment. HortScience 29:749-751. 1994.

JEFFRIES, P., DODD, J.C., JEGER, M.J. \& PLUMBLEY, R.A. The biology and control of Colletotrichum species on tropical fruit crops. Plant Pathology 39:343-366. 1990.

LANTICAN, M.T. \& QUIMIO, T.H. Pathogenicity and cultural characteristics of Botryodiplodia spp. causing fruit rots. Philippine Phytopathology 12:66-74. 1976.

LIBERATO, J.R., VANETTI, C., RODRIGUES, C.H. \& DIAS, V.P. Ocorrência de podridão de Phytophthora em mamoeiro (Carica papaya L.) no Estado do Espírito Santo. Fitopatologia Brasileira 18:324. 1993.

MEDINA, J.C. Cultura. In: Medina, J.C., Bleinroth, E.W., Sigrist, J.M.M., De Martin, Z.J., Nisida, A.L.A.C., Baldini, V.L.S., Leite, R.S.S.F. \& Garcia, A.E.B. (Eds.) Mamão: cultura, matéria-prima, processamento e aspectos econômicos. $2^{\mathrm{a}}$ ed. Campinas. ITAL. 1989. (Frutas tropicais, 7).

NERY-SILVA, F.A., MACHADO, J.C., LIMA, L.C.O. \& RESENDE, M.L.V. Controle químico da podridão peduncular de mamão causada por Colletotrichum gloeosporioides. Ciência Agrotécnica 25:519-524.
2001.

NISHIJIMA, W.T., DICKMAN, M.B., KO., W.H. \& OOKA, J.J. Papaya diseases caused by fungi. In: Ploetz, R.C., Zentmyer, G.A., Nishijima, W.T., Rohrbach, K.G. \& Ohr, H.D. (Eds.) Compendium of tropical fruit diseases. St. Paul. APS Press. 1994. pp.58-64.

PAULL, R.E., NISHIJIMA, W., REYES, M. \& CAVALETTO, C.C. Postharvest handling and losses during marketing of papaya (Carica papaya L.). Postharvest Biology and Technology 11:165-179. 1997.

PERES, A.P., MACHADO, J.C., CHITARRA, A.B. \& LIMA,L.C.O. Perfil enzimático de fungos associados à podridão peduncular do mamão. Ciência Agropecuária 24:295-299. 2000.

PLOETZ, R.C., ZENTMYER, GA., NISHIJIMA, W.T., ROHRBACH, K.G. \& OHR, H.D. Compendium of tropical fruit diseases. Minessota. APS Press. 1994.

PRUSKY, D. Pathogen quiescence in postharvest diseases. Annual Review of Phytopathology 34:413-434. 1996.

REZENDE, J.Á.M. \& FANCELLI, M.I. Doenças do mamoeiro (Carica papaya L.). In: Kimati, H, Amorim, L., Bergamin Filho, A., Camargo, L.E.A. \& Rezende, J.A.M. (Eds.) Manual de fitopatologia - doenças das plantas cultivadas. São Paulo. Agronômica Ceres. 1997. pp.486-496.

ROSSMAN, A.Y., PALM, M.E. \& SPIELMAN, L.J. A literature guide for the identification of plant pathogenic fungi. St. Paul. APS Press. 1994.

SILVA, G.S. Podridão das raízes e dos frutos do mamoeiro. In: Luz, E.D.M.N., Santos, A.F., Matsuoka, K. \& Bezerra, J.L. (Eds.) Doenças causadas por Phytophthora no Brasil. Campinas. Livraria e Editora Rural Ltda. 2001. pp.413-432.

SILVEIRA, N.S.S., MICHEREFF, S.J., MARIANO, R.L.R., MAIA, L.C. \& OLIVEIRA, S.M.A. Hongos fitopatógenos asociados a frutos comercializados en Recife, Pernambuco (Brasil). Boletín Micológico 16:41-47. 2001.

SINGH, G., RIPPON, L.E. \& GILBERT, W.S. 2,4-D residues in stored lemons from post-harvest treatments. Australian Journal of Experimental Agriculture and Animal Husbandry 17:167-170. 1977. SNOWDON, A.L. A color atlas of post-harvest diseases \& disorders of fruits \& vegetables - general introduction \& fruits. London. Wolfe Scientific. v. 2. 1990.

ZAMBOLIM, L., COSTA, H., VENTURA, J.A. \& VALE, F.X.R. Controle de doenças em pós-colheita de frutas tropicais. In: Zambolim, L. (Ed.) Manejo integrado:fruteiras tropicais - doenças e pragas. Viçosa. UFV. 2002. pp.443-511.

ZAUBERMANN, G. \& BARKAI-GOLAN, R. Changes in respiration and ethylene evolution induced by Diplodia natalensis in orange fruit. Phytopathology 65:216-217. 1975. 